10.1590/S1414-40772018000300002

Este é um artigo publicado em acesso aberto sob uma licença Creative Commons

https://creativecommons.org/licenses/by-nc/4.0/

\title{
Diagnóstico rápido participativo como método de pesquisa em educação
}

Jeferson Antunes ${ }^{1}$

\author{
Abigayl Fernandes da Silva² \\ Ana Clarice Bezerra de Araújo Silva ${ }^{3}$ \\ Zuleide Fernandes de Queiroz ${ }^{4}$
}

Resumo: A pesquisa em educação dialoga com a epistemologia, a história da universidade pública e da democracia no Brasil, onde observamos a iminência dos métodos e técnicas qualitativas e quantitativas, os chamados métodos mistos. No entanto, as formações nos cursos de graduação não compreendem tal multiplicidade, cabendo a pesquisadores e grupos de pesquisa buscarem e divulgarem tais métodos e abordagens. Baseados nesta compreensão, propomos a utilização do Diagnóstico Rápido Participativo (DRP) como método misto para pesquisa educacional, este utiliza de vários métodos para apreensão da realidade local, através da mediação entre pesquisadores e participantes, em um processo ativo e reflexivo quanto a realidade. Nosso objetivo é compreender como o DRP pode ser utilizado para o diagnóstico na pesquisa em educação; ademais, desejamos descrever as etapas de construção e as possíveis ferramentas utilizadas no DRP em educação e discutimos como o DRP pode corresponder aos limites e possibilidades da pesquisa educacional. Assim, utilizamos pesquisa bibliográfica e análise narrativa visando compreender como surge a necessidade de utilização de métodos mistos e como o DRP pode contribuir. O DRP é uma metodologia flexível, auxiliando o contorno de possíveis problemas na pesquisa; possibilita triangulação de dados, contribuindo para aumentar a confiabilidade dos resultados; facilita a utilização de métodos mistos para a aquisição e interpretação dos dados através da reflexão participativa sobre possíveis ações que resultem na resolução dos problemas encontrados durante o processo da pesquisa e tem, tanto no processo, como no resultado esperado, uma forte contribuição social aos participantes.

Palavras-chave: Pesquisa em educação. DRP. Métodos mistos.

\section{Rapid participatory appraisal as a research method in education}

Abstract: There is a dialogue between epistemology, history of public university and democracy in Brazil and research in education, where we observe the need for methods and qualitative and quantitative techniques, called Mixed Methods. However, training with undergraduate courses do not understand such a multitude, leaving researchers and research groups seek and disseminate such methods and approaches. Based on this understanding, we propose the use of Rapid Participatory Appraisal (DRP) as a Mixed Methods for educational research, it uses various methods to arrest the local reality through mediation between researchers and participants in an active and reflective process as reality. Our goal is to understand how DRP can be used for diagnosis in research in education; In addition, we wish to describe the stages of construction and the possible tools used in DRP in education and we discuss how the DRP can correspond to the limits and possibilities of educational research. For this, we use the methods of bibliographic research and narrative analysis, trying to understand how the use of mixed methods arises and how DRP can contribute. DRP is a flexible methodology, aiding the outline of possible problems in the research; Allows for triangulation of data, contributing to increase the reliability of results; Facilitates the use of mixed methods for the acquisition and interpretation of data through participatory reflection on possible actions that result in the resolution of problems encountered during the research process and has a strong social contribution to the participants both in the process and in the expected result

Key words: Research education. DRP. Mixed methods research. 


\section{Introdução}

No campo da pesquisa em educação, os pesquisadores que investigam as relações sociais em instituições de ensino, formais e informais, balizam seus objetivos de pesquisa visando compreender a realidade estudada, neste contexto, a metodologia é o coração da pesquisa, uma vez que propicia a aquisição destes objetivos.

Entre 1960-1970, o campo da pesquisa em educação convergia para estudos de natureza quantitativa, visando a compreensão da realidade educativa de forma generalista; entre 1980-1990, o campo é tomado pela abordagem de natureza qualitativa, visando o entrelaçamento com as realidades a serem estudadas, a partir das relações sociais e da análise micro da realidade.

Constata-se, atualmente, que os métodos e técnicas que pretendem uma interação entre as abordagens qualitativa e quantitativa têm sido cada vez mais utilizados, essa conexão possibilita uma visão mais fidedigna dos microcosmos a serem estudados (GATTI, 2012). Os métodos e técnicas de natureza mista se apresentam como tendência, um paradigma emergente do campo, tendo em vista que, ao investigar essas realidades tão distintas, apenas os dados quantitativos ou qualitativos podem não ser mais capazes de abarcar o todo, onde os resultados apresentados podem acabar por se tornando um recorte pobre da realidade estudada.

Os pesquisadores se apropriam cada vez mais da multiplicidade de abordagens possíveis, visando uma aquisição mais rica e fidedigna da realidade que corrobore para a aquisição de seus objetivos de pesquisa. Para que isto ocorra, a formação acadêmica necessita convergir à esta multiplicidade, o que de não condiz com a realidade, visto que nossa formação é permeada por estruturas positivistas (DAL-FARRA; LOPES, 2013; GATTI, 2012). Desta forma, reconhecer as possibilidades interdisciplinares de métodos e técnicas de pesquisa, a possibilidade de múltiplas abordagens, o diálogo entre o micro e o macro, e as contribuições cientificas advindas destas interações se tornam processos complexos aos pesquisadores.

Compreendendo tais lacunas da pesquisa em educação, propomos a utilização, do Diagnóstico Rápido Participativo (DRP) como método misto para a pesquisa em educação. Este, advêm do campo da pesquisa rural, visando a utilização de métodos para a apreensão da realidade local, a partir da participação ativa dos indivíduos em um processo de reflexivo, tendo os pesquisadores o papel de mediar as interações entre os participantes visando a descoberta de possíveis soluções para os problemas encontrados (VERDEJO, 2010). 
O objetivo principal deste estudo é o de compreender como o DRP pode ser utilizado para o diagnóstico na pesquisa em educação. Especificamente temos como objetivos descrever as etapas de construção e as possíveis ferramentas utilizadas no DRP em educação e discutir como o DRP pode corresponder aos limites e possibilidades da pesquisa educacional.

Para tal aporte nos utilizamos da pesquisa bibliográfica (GIL, 2012), através de uma análise narrativa (ROTHER, 2007) do campo da pesquisa em educação, para compreendermos melhor como surge a necessidade de utilização de métodos mistos e como o DRP pode vir a contribuir para as lacunas apresentadas.

Observamos que o DRP se apresenta como uma metodologia flexível, auxiliando o contorno de possíveis problemas na pesquisa de campo; possibilita a triangulação de dados, contribuindo para aumentar a confiabilidade dos resultados obtidos; apresenta como característica a utilização de métodos mistos para a aquisição e interpretação dos dados em um processo onde os participantes refletem, junto com os pesquisadores, sobre possíveis ações que resultem na resolução dos problemas encontrados durante todo o processo da pesquisa.

Outros métodos têm vantagens similares as apresentadas pelo DRP, a exemplo do Estudo de Caso. A escolha do DRP se dá pela participação da comunidade no processo de pesquisa, onde estes são movidos a refletir sobre o contexto e as possibilidades de resolução dos problemas, além disso, todo DRP só é finalizado quando os pesquisadores apresentam e revisão, junto à comunidade, um relatório propositivo com todo o conteúdo sistematizado. Não é só o processo de pesquisa, mas o resultado da pesquisa, que contribui socialmente para uma possível mudança de rumo ante a reflexão mediada com uso da metodologia.

\section{Metodologia}

O presente estudo é desenvolvido a partir de pesquisa bibliográfica (GIL, 2012, p. 50), dialogando acerca das naturezas de pesquisa em educação, da necessidade do uso de métodos mistos e do DRP como metodologia de pesquisa. Procedemos à uma revisão narrativa, através de artigos em revistas eletrônicas, impressos e livros, onde o leitor pode, em um curto espaço de tempo, adquiri e atualizar seus conhecimentos sobre a temática proposta (ROTHER, 2007).

Nossa finalidade é a de esclarecer e descrever conceitos e ideias, contribuindo para o campo da pesquisa em educação, ao apresentar uma síntese metodológica através da pesquisa exploratória e da pesquisa descritiva (GIL, 2012). 


\section{Pesquisa em educação no Brasil}

As questões acerca dos limites e possibilidades dos métodos, abordagens e naturezas da pesquisa em educação compreendem um conjunto de mudanças no campo epistemológico, político e da difusão da ciência e tecnologia no Brasil, reforçado pela ampliação do ensino superior no nível de graduação e pós-graduação. A condição histórica da pesquisa em educação dialoga com a história da Universidade e da Democracia em nosso país.

Com a criação do Instituto de Pesquisas Educacionais (IPE), anos 30, temos a primeira sistematização de estudos no campo da educação, estes, até os anos 50, se situavam em temas ligados a psicopedagogia, pós 56 os centros de pesquisa se vinculam ao Instituto Nacional de Estudos e Pesquisas Educacionais (INEP) e apresentam uma abordagem sociológica da educação, essa abordagem é interrompida no golpe militar de 64 , onde as pesquisas tomam um caráter economicista, visando auferir custos e gastos do sistema educacional (GATTI, 2001).

No contexto de 64 "a pesquisa educacional foi se integrando às novas perspectivas, como uma forma de crítica social, criando espaços mais abertos e democráticos, com fundamentação marxista” (SANTOS; GRAEFF; KERN; DENTZ, 2016, p. 50).

No ano de 68, o governo militar estabelece a reforma universitária, nesse período a ampliação dos programas de pós-graduação em educação contribui para a produção de estudos e pesquisas, sendo a maior parte destes ligados aos programas de mestrado e doutorado; no final dos anos 70 surge a Associação Nacional de Pós-Graduação e Pesquisa em Educação (ANPED), que fortalece a pesquisa em educação através de seus grupos de trabalho (GATTI, 2001; CAMPOS; FAVERO, 1994).

As pesquisas em educação se ampliam e intensificam na década de 80, com a propagação de metodologias como a pesquisa-ação, que é realizada em associação com uma ação coletiva no qual os pesquisadores e os participantes estão envolvidos de modo cooperativo (THIOLLENT, 1996); e também a teoria do conflito, que representa a disputa entre grupos com posições distintas sobre um determinado tema/contexto, tendo como pano de fundo o modelo de desenvolvimento social de um grupo coletivo específico (SANTOS, 2014). Estas metodologias são impulsionadas pelo descrédito nas soluções técnicas e sua inabilidade em resolver os problemas educacionais brasileiros, desta forma, a abordagem crítica e participativa se apresenta como opção para as necessidades postas (ANDRÉ, 2007).

Nos anos 60-70 o interesse estava na experimentação, no olhar do pesquisadorobservador do experimento, nos anos 80-90 recebem espaço as pesquisas acerca de situações 
reais, tendo o pesquisador papel de participante, assim, os "estudos que nas décadas de 60-70 se centravam na análise das variáveis de contexto e no seu impacto sobre o produto, nos anos 80 vão sendo substituídos pelos que investigam sobretudo o processo" (ANDRÉ, 2007, p. 121). A racionalidade limitada a um mundo ordenado divide espaço com a complexidade das relações sociais, aproximando o pesquisador de seu objeto/sujeito de pesquisa. A escola, a comunidade e a sociedade são investigados também no microcosmos interacional.

As duas formas do oficio se encontram e confrontam, dialogam e antagonizam; entre micro e macro, local e global, cada uma com objetivo basilar de dialogar com os contextos educativos no Brasil. Os antagonismos são claros, diversos grupos científicos, acadêmicos e não acadêmicos, tomam o campo de produção científica em educação com opções epistemológicas, abordagens e posicionamentos políticos diferentes (CAMPOS, 2006).

O que acontece no campo da educação é a falta de dados que nos ajudem a melhor responder aos problemas ao qual, como pesquisadores, nos propomos a investigar, os dados quantitativos generalistas são complexos quando pensamos a partir do microcosmos social não sendo tão úteis para responder a estas demandas específicas (GATTI, 2012). A coleta e a análise de dados quantitativos respondem a demandas de instituições governamentais e transnacionais, que financiam as pesquisas de grande amplitude, com um perfil mais pragmático, colhidos em sistemas centralizados de avaliação ou em universos estatísticos mais amplos, para oferecer resultados a curto prazo para a criação e implementação de modelos (CAMPOS, 2006).

A realidade dos problemas educacionais é mais diversa que os dados sistematizados e homogeneizados podem afirmar, e mais ampla que as análises dos microcosmos sociais conseguem perceber. Em alguns momentos são necessários dados mais amplos, como para a discussão do analfabetismo populacional como um problema políticos, ou mesmo um aprofundamento de natureza social, como no caso da dinâmica sócio-pedagógica em uma escola (GATTI, 2012). Essa dicotomia acadêmica sugere um aparente estado irreconciliável das ciências da educação, posto como grupos antagônicos sobre a influência da academia, das instituições e das escolhas políticas.

Estes diálogos dicotômicos da ciência se apresentam como tentativas de afiliar-se a um paradigma posto que, supostamente, concede ao pesquisador a credibilidade e acreditação necessária para galgar caminho entre os pares. Essa propensa dicotomia não se sustenta para julgar o valor científico de um estudo, ela apenas significa uma escolha, muitas vezes imposta pela academia, sendo um 
aspecto a considerar é que as mensurações quantitativas, tanto quanto as tematizações ou categorizações qualitativas (com base em observações cursivas, entrevistas, questionários abertos, depoimentos etc.) são aproximações do fenômeno a ser estudado e o problema levantado, não são o próprio fenômeno (GATTI, 2012, p. 30).

Os critérios dentro do paradigma escolhido pelo pesquisador não são a realidade, não bastam por si só, eles se apresentam como lentes para enxergarmos o fenômeno social, que em sua complexidade pode ser analisado sobre diversos ângulos complementares. "Todas as formas de obtenção de informações e de dados são criadas, inventadas, consensuadas e não podem ser tomadas como a própria natureza das coisas, muito menos a totalidade da realidade" (GATTI, 2012, p. 30).

A pesquisa em educação, não sendo fim em si mesma, aporta-se como um conjunto de reflexões nascidas da experiência, das análises teóricas e da experimentação em que buscamos concatenar ideias e realidade que pretendemos interpretar. Historicamente postas, as amarras paradigmáticas dos princípios firmes, irrefutáveis e obrigatórios devem ser repensadas. É necessário violar esse dogmatismo para que a ciência possa vir a contribuir qualitativa e quantitativamente frente aos problemas complexos que desejamos explorar, fugir de soluções obvias é uma necessidade para a mudança da realidade social (FEYERABEND, 1977, p. 29).

Faz-se necessário, portanto, que a diversidade de métodos, ferramentas, formas de coleta e análises de dados sejam pensados a partir e sobre o contexto que desejamos elucidar. "Estamos refletindo com os dados e análises básicas, porém, também transcendendo esses dados e análises iniciais com fundamento argumentativo sólido" (GATTI, 2012, p. 31). Essa renovação não se alicerça em abandonar os fundamentos científicos em prol de uma propensa liberdade metodológica, mas utilizar destas formas paradigmáticas para contextualizar o problema que, quando bem fundamentadas, possibilitam ao pesquisador do campo da educação uma formulação dinâmica para explicar da melhor forma possível o fenômeno estudado.

No campo contemporâneo da pesquisa em educação observamos, nos últimos anos, “o uso combinado de formas de abordagem, sob a égide de uma perspectiva que conduziu à enunciação do problema e que baliza os caminhos das análises e interpretações oferecidas" (GATTI, 2012, p. 31). A estatística descritiva aliada as entrevistas em profundidade, a análise clínica entrelaçada aos estudos experimentais, os estudos quase-experimentais combinados a entrevistas abertas, dados e indicadores demográficos aliados a etnografia, o próprio estudo etnográfico utilizando de questionário como ferramenta de coleta de dados para uso e construção de escala de valores; tais abordagens combinadas envolvem análises quantitativas 
e qualitativas integradas e contrastadas segundo eixos analíticos, que permitem interpretações de diversas naturezas (GATTI, 2012, p. 31).

\section{Reflexões sobre natureza da pesquisa em educação}

A partir das mudanças históricas do campo da pesquisa em educação observamos que a pesquisa qualitativa, de forma crítica e participativa, ganha espaço no campo de estudos, sendo esta "de particular relevância ao estudo das relações sociais devido a pluralização das esferas da vida" (FLICK, 2009, p. 20), onde as interações sociais se mostram mais complexas e dinâmicas, em seu microcosmo, quando comparadas as abordagens apresentadas pelas pesquisas de natureza quantitativas.

Existe uma grande incidência de estudos qualitativos em educação, o que é coerente, visto seu desenvolvimento histórico, contudo, o uso de métodos quantitativos para estudos em larga escala nos possibilita uma visão panorâmica do objeto e/ou dos sujeitos do estudo, o que se apresenta como um outro tipo de contribuição para investigar o macrocosmo social em vistas a compreender questões mais gerais e abrangentes (PEREIRA; ORTIGÃO, 2016, p. 6870).

Ambas as naturezas de pesquisa, na perspectiva contemporânea da pesquisa em educação, devem dialogar, o que exige do pesquisador uma maior preparação e a abertura interdisciplinar para outros campos de pesquisa (GATTI, 2001), tendo em vistas que tanto o quantitativo como o qualitativo, e suas imbricações, são possibilidades de qualquer pesquisa (MINAYO, 2013) ressaltando a existência de limites e possibilidades de ambas as naturezas.

Pensar a realidade dinâmica nas interações entre micro e macro, possibilita ao pesquisador a escolha de uma maior diversidade de métodos e técnicas que o auxilie na busca por compreender os problemas de pesquisa abordados.

O uso de métodos mistos de pesquisa, qualitativos e quantitativos, pode proporcionar as pesquisas em educação um corpus mais organizado do conhecimento, com a contribuição de ambas as naturezas, o que gera respostas mais abrangentes aos problemas de pesquisa formulados oriundo de diversas perspectivas (DAL-FARRA; LOPES, 2013, p. 71-79).

Este processo exige um entendimento mais apurado, por parte dos pesquisadores, sobre as possibilidades de interação e as informações disponíveis, necessitando de um entendimento claro sobre os limites e possibilidades das escolhas metodológicas no momento de aplicar os métodos escolhidos e analisar os dados coletados (DAL-FARRA; LOPES, 2013, p. 71-79). 
Para análise do microcosmos interacional em pesquisa educacional, refletindo a partir de métodos mistos, este artigo propõe a utilização do Diagnóstico Rápido Participativo (DRP), que pode ser transposto para a pesquisa em educação, uma vez que possibilita o diálogo de forma participativa e critica com as comunidades e problemas que se deseje investigar.

\section{Diagnóstico rápido participativo}

A origem do DRP remota a projetos rurais desenvolvidos, na década de 70, na África e Ásia, por organizações europeias que buscavam métodos não-generalistas e que apresentassem informações detalhadas das comunidades rurais investigadas (PEREIRA, 2001, p. 5).

As limitações dos métodos anteriores surgiam na certeza de que as transferências tecnológicas resolveriam os problemas das comunidades e também na ausência da participação dos favorecidos, que resultavam em documentos que não condiziam com as necessidades e a realidade das comunidades abordadas (VERDEJO, 2010, p.13).

O contexto histórico do DRP aponta a um momento de transição paradigmática, em um contexto de necessária ausência de participação e reconhecimento dos atores locais para sua efetiva participação e reconhecimento na elaboração dos projetos. O DRP é um método proposto para avaliar as necessidades de uma comunidade, onde uma equipe multidisciplinar compartilha com a comunidade uma variedade de tarefas para coleta de dados, análise de dados e definir prioridades com base nessas análises (RIFTKIN, 1996; CHAMBERS, 1981; CARRUTHERS; CHAMBERS, 1981).

Várias críticas foram tecidas ao DRP na década de 1980, principalmente acerca da aquisição e análise de dados considerada abrupta e com pouco tempo de maturação e reflexão (CHAMBERS, 1992). Vários técnicos e pesquisadores, reconhecendo a natureza destas críticas, sugeriram um foco renovado no aspecto participativo ante a rapidez da coleta de dados, isso ocasionou uma mudança tanto da abordagem quanto na nomenclatura.

A partir da reflexão sobre a crítica surge o Diagnóstico Rural Participativo (DRuP), definido como "uma família crescente de técnicas e métodos para permitir que os atores locais compartilhem, aprimorem e analisem seus conhecimentos da comunidade e condições para planejar e agir ante sua realidade" (CHAMBERS, 1992, p. 1, tradução nossa).

O DRuP tem por objetivo fomentar a autoanálise e a autodeterminação de grupos comunitários, através da obtenção de dados fornecidos pelos participantes em contato com a 
equipe mediadora, onde a participação, o reconhecimento dos saberes locais e a visão sistêmica corroboram para a aquisição desses objetivos (VERDEJO, 2010, p. 13).

Outra apropriação da metodologia é o Diagnóstico Rápido Participativo Emancipador (DRPE) a qual foi desenvolvida para trabalhar as complexidades dos assentamentos rurais brasileiros, possibilitando recolher dados tanto quantitativos quanto qualitativos, sendo aplicada ao longo do ano de 1997 (PEREIRA, 2001, 1998).

O termo "emancipador" que é acrescido à metodologia tem sua fundamentação na abordagem Freriana, sendo, portanto, esperado que a aplicação das técnicas de DRPE resultem na formação da consciência dos participantes, em vistas à emancipação destes em relação a dependência e tutoria (PEREIRA, 2001, 1998).

Existem também experiência do DRuP como ferramenta no contexto educacional. $\mathrm{Na}$ unidade educativa Luis Beltrán Ramos, localizada na freguesia de Juana de Ávila no Município de Maracaibo, Estado de Zulia, na Venezuela, a metodologia foi utilizada para dar origem a um Proyecto Educativo Comunitario (PPC) (AMADO; CRISTALINO; HERNÁNDEZ, 2004).

Para este caso, o DRP foi utilizado para identificar, definir e sistematizar os problemas da unidade escolar, tendo como objetivo elaborar estratégias para a solução destes problemas e estabelecer um plano de desenvolvimento destinado aos membros da comunidade e organizações circunvizinhas (AMADO; CRISTALINO; HERNÁNDEZ, 2004, p. 96).

O DRP caracteriza-se como metodologia que considera diferentes enfoques e multidisciplinariedade de técnicas e pesquisadores que desejem compreender e mediar possibilidades para solucionar problemas elencados na comunidade, traçando um plano de ação que acompanhe a evolução do processo, a partir da participação ativa e da interação dialógica, podendo resultar na emancipação dos envolvidos (PEREIRA, 2001; CHAMBERS, 1992).

A partir das pesquisas que utilizam DRP como método, este vem se aprimorando, sobretudo em projetos ligados às comunidades rurais, sendo usado por entidades e organizações quase que obrigatoriamente nos assentamentos rurais do Brasil, visando o diagnóstico e o planejamento socioeconômico das comunidades (SOUZA, 2009, p. 35). Algumas perguntas surgem neste ponto: Podemos utilizar esta metodologia no campo da pesquisa em educação? Quais seriam os procedimentos? Quais seriam os limites e as possibilidades? De que maneira ela pode dialogar com a realidade? No próximo ponto abordamos essas inquietações. 


\section{Processo, limites e possibilidades do diagnóstico rápido participativo em educação}

O DRP constitui-se, como estrutura de pesquisa de natureza mista, por diversas fases. As fases de início e contato são primordiais para a efetivação da pesquisa de campo, uma vez que as práticas participativas para o delineamento da pesquisa, escolha de métodos e ferramentas, devem ser pautadas na participação ativa dos indivíduos da comunidade. Para iniciarmos nossa abordagem sobre o uso do DRP em pesquisa educacional, apresentamos um diagrama que resume suas fases e processos:

\section{Figura 1 - Diagrama do processo de pesquisa do DRP}

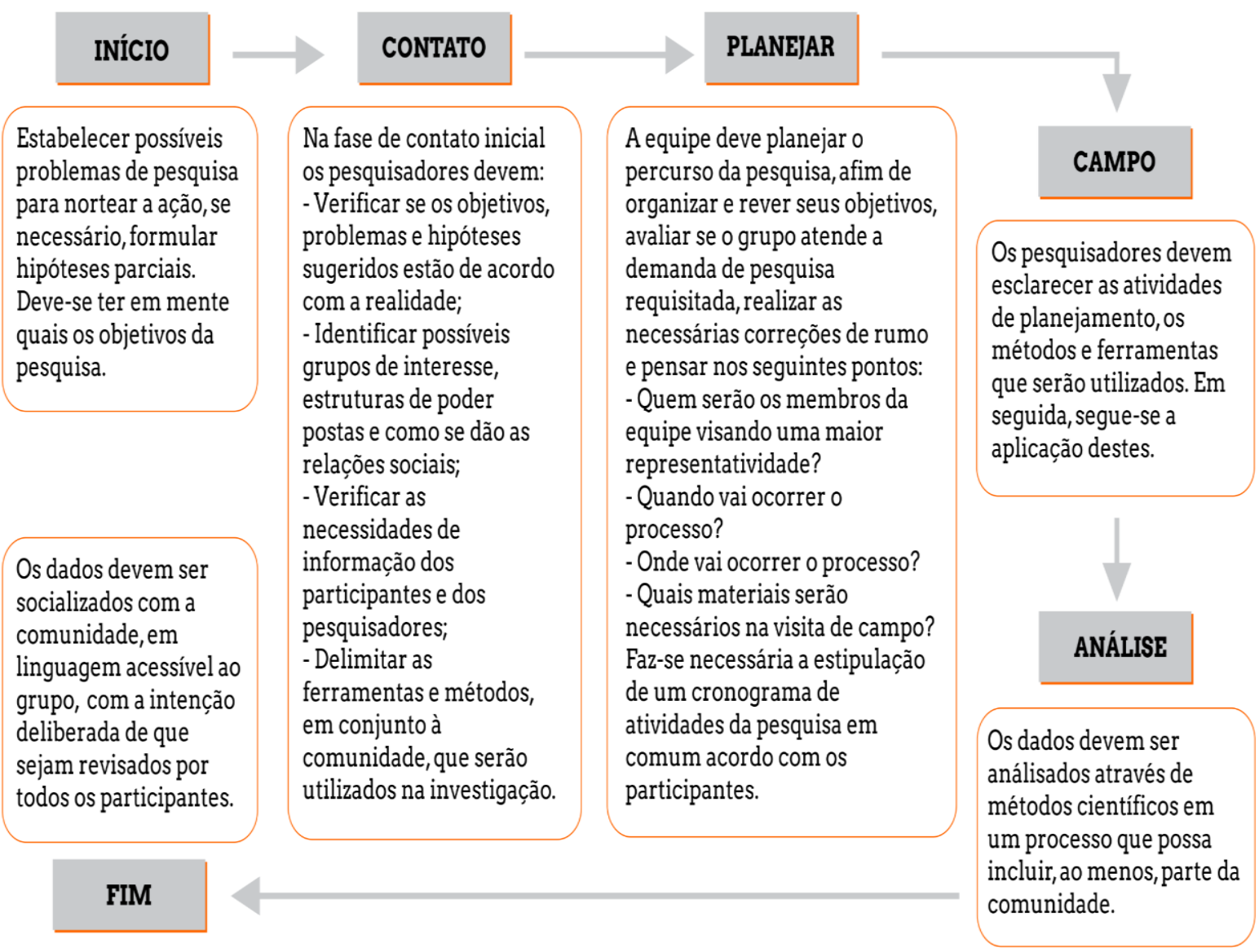

Fonte: Formulado pelos autores.

Os pesquisadores devem ter em mente que no DRP, à comunidade educativa ${ }^{1}$ é parte de todo processo, isso contribui para compreendermos as relações e os procedimentos

1 Utilizamos o termo comunidade educativa a partir da compreensão de que a educação se dá em diversos níveis e etapas da vida; com uma multiplicidade de atores participando desse processo e variadas instituições (formais e não formais), ao qual deve ser pensada por meio da colaboração, interação e do trabalho em grupo. 
educativos a partir da colaboração e interação entre os indivíduos e o mundo. Isso vai de encontro ao pensamento de Paulo Freire $(1996,1991)$, quando argumenta que a educação é realizada na interação entre os indivíduos, construída a partir da interação com o mundo em que vivem, onde estes podem começar a ler o mundo, mesmo antes da leitura da palavra, compreendendo bem mais que o escrito sobre aquilo que é realmente significativo em suas vidas.

No contexto escolar brasileiro, herdado de uma estrutura patrimonialista e positivista, a desagregação dos grupos através das estratificações sociais por etnia, gênero, poder aquisitivo, orientação sexual e religiosa, propicia um espaço desagregador (LOURO, 1997), que pode vir a limitar a pesquisa que utiliza o DRP como método.

No entanto, um bom planejamento e contato com à comunidade pesquisada, nos fornece a possibilidade de perceber como se dão estas relações nos vários níveis; visando analisar, compreender e refletir, em conjunto à comunidade educativa, como se produzem e reproduzem estas estratificações, quais seus possíveis efeitos sobre os sujeitos e a comunidade, buscando perceber se/como elas existem e quais as possíveis formas de resistência (implícitas e explícitas), por parte da comunidade educativa.

Tendo como ideia fundante esta multiplicidade de relações e atores nos processos educativos, é importante para os pesquisadores estabelecer, na fase inicial, qual tipo de trabalho irá ser realizado junto à comunidade, identificar como esse diagnóstico será traçado, se este lidará com um problema novo ou antigo, e ainda, se este é geral ou enfoca aspectos particulares (VERDEJO, 2010). Esta fase envolve preparação e reflexão quanto a problematização da comunidade educativa, bem como, a delimitação dos objetivos e a geração de hipóteses provisórias (caso necessário) que nortearão os próximos passos da pesquisa.

A fase de contato com os participantes facilitará o andamento do DRP e auxiliará na tomada de decisão ante o propenso problema de pesquisa a ser estudado, podendo ser realizado a partir de visitas combinadas, uma vez que os pesquisadores têm seu primeiro contato com o que realmente desejam compreender. Um cuidado importante nesta fase é que se tome nota de todas as informações possíveis, garantindo que não exista perda de dados relevantes (VERDEJO, 2010).

$\mathrm{Na}$ fase de contato, podem ser ofertados espaços de discussão e cursos básicos, afim de estimular os participantes as práticas do processo participativo que estarão presentes, o que pode aumentar a confiança entre os membros do grupo e para com os mediadores (FREITAS; FREITAS; DIAS, 2012, p. 71). A equipe deve ter cuidado com a linguagem utilizada, de 
acordo com o público participante, esta deve ser compreensível e estar alinhada à realidade, o que facilita o processo de pesquisa, também nas fases de campo e final.

Nesta fase, os pesquisadores devem tentar identificar quais grupos de interesse, dentro da comunidade educativa, estão inseridos no contexto do trabalho que será desenvolvido, quem são os lideres, quem representa a comunidade, se homens e mulheres participam igualmente dos processos (VERDEJO, 2010).

Outro limite/possibilidade que a equipe deve estar atenta, diz respeito ao grupo que irá auxiliar a comunidade. Este deverá ser o mais interdisciplinar possível, as particularidades de cada mediador, como gênero, áreas de pesquisa, credo, etnia e idades distintas garantem que sejam feitas análises do problema a partir de diversas perspectivas (VERDEJO, 2010, p. 21).

Uma equipe interdisciplinar colabora articulando de forma criativa, colaborativa e responsável, saberes que busquem a resolução de situações problema, limitados pelo saber compartimentalizado, sendo uma "ação do conhecimento que consiste em confrontar saberes, cuja finalidade é alcançar outro saber, mais complexo e integral, diferente daquele que seria efetuado, caso não exista o encontro entre diferentes disciplinas" (FLORIANI, 2000, p. 11).

Esse misto de pesquisadores deve sempre respeitar a cultura e sabedoria da comunidade em que escolheram desenvolver o projeto, pois o povo é criativo e capaz, e o diálogo com/entre os saberes dos participantes dão margem à resolução do problema ou conflito (HERNÁNDES, 2013, p. 56)

Os participantes do DRP provavelmente esperam ser beneficiados de alguma forma ao longo do processo de diagnóstico, visando isso, é importante que o processo revele a real situação do grupo e torne os participantes aptos a realizar mudanças (VERDEJO, 2010, p. 22). A função do DRP é mediadora e não apenas a coleta e análise sistemática dos dados, nesse momento inicial não é recomendável criar expectativas que talvez nem possam ser cumpridas.

A discussão entre os membros do grupo sobre o que esperam do DRP é uma oportunidade de discutir as variadas necessidades e nortear os objetivos de pesquisa. Essas expectativas são pontos que podem ser explorados pela equipe mediadora para construir um plano mais próximo da realidade e necessidades prioritárias na fase planejar.

Neste ponto as necessidades de informação dos participantes e dos mediadores devem ser discutidas, visando tornar o trabalho mais objetivo possível (VERDEJO, 2010, p. 22-23). Os mediadores devem estar atentos aos dados apresentados pelos participantes durante todo o processo, sejam eles econômicos ou culturais, é importante aproveitar toda a informação disponível acerca do conhecimento da comunidade e seus problemas nesse contato inicial (AMADO; CRISTALINO; HERNÁNDEZ, 2004). 
O DRP é uma metodologia que buscar escutar a todos, para que isso ocorra de forma efetiva, os mediadores devem utilizar diversas ferramentas e metodologias, conhecidas como caixa de ferramentas. Esta caixa de ferramentas deve ser adequada a realidade em que desejamos atuar, realizar entrevistas onde sabemos que pessoas não têm uma boa aceitação com gravadores, ou requerer que grupos semialfabetizados redijam textos, é inconcebível.

Entre possibilidades da caixa de ferramentas podemos utilizar de observação participante, entrevistas semiestruturadas, construção coletiva de mapas e maquetes, realização da travessia/caminhada transversal, utilização de calendários, confecção colaborativa de diagramas, uso de matrizes e realizar análises de gênero (VERDEJO, 2010, p. 28-61).

Para pesquisa em educação uma série de formas de obtenção e análise de dados podem compor a caixa de ferramentas, auxiliando os pesquisadores na obtenção dos dados necessários. Recomendamos, para aquisição de dados, o uso de Mapas Afetivos, utilizado para o reconhecimento de espaços educativos e dos sentimentos implícitos na percepção sobre estes espaços (BONFIM, 2003); design thinking, um processo colaborativo para reconhecimento e gerenciamento de problemas e soluções apresentadas (DUNNE; MARTIN, 2006); a utilização de filmes, documentários e animações (como forma de abrir caminho para o diálogo entre os participantes); e os jogos colaborativos que, nesse contexto, podem ser utilizados como ferramenta de sensibilização, fortalecendo o grupo quanto espaço participativos através do impacto lúdico (ANTUNES; LIMA; TEIXEIRA; SOUSA; CAVALCANTE, 2016).

Para a análise de dados consideramos a utilização do Discurso do Sujeito Coletivo, um método qualiquantitativo utilizado para analisar entrevistas, ponderando sobre os discursos dos participantes e o tema explorado oferecendo aos pesquisadores uma síntese dos dados qualitativos onde, a partir destes, são mensurados elementos quantitativos relevantes (LEFEVRE; LEFEVRE, 2012); a Análise Temática, que visa identificar, analisar e reportar temas acerca de dados estruturados, ela organiza e descreve estes dados em ricos detalhes, buscando interpretar vários aspectos do discurso analisado (BRAUN; CLARKE, 2008); e a Análise Semiótica que "prove o analista com um conjunto de instrumentais conceptuais para uma abordagem sistemática dos sistemas de signos, a fim de descobrir como eles produzem sentido" (PENN, 2007, p. 319); como formas de interpretar a diversidade de dados obtidos.

Quanto a utilização de dados secundários advindos de sistemas de avaliação centralizados, estes se apresentam como ótimas referências para balizar discussões entre os participantes. Ao se discutir, por exemplo, dados do Sistema Nacional de Avaliação do 
Ensino Básico (SABE) ante a realidade escolar, os pesquisadores podem auferir como estes convergem, apontando necessidades de mudanças de rumo e proposições para novas metodologias e pesquisas que explicitem características globais mais interessantes para os problemas educativos. Temos aqui um campo de diálogo muito importante, onde o micro pode apresentar capacidade de diálogo real com o macro por meio da reflexão dialógica.

O uso dessas ferramentas e metodologias, selecionadas a partir do contato com os participantes, permite que os pesquisadores obtenham uma visão da realidade, que de outra maneira, seria difícil de considerar (HERNÁNDES, 2013, p. 55). Uma vantagem desta multiplicidade metodológica está na capacidade de triangulação dos dados, esta "permite obter, de duas ou mais fontes de informação, dados referentes ao mesmo acontecimento, a fim de aumentar a confiabilidade da informação" (MEIRINHOS; OSÓRIO, 2010, p. 60).

Desta forma, pensar a utilização de métodos e ferramentas para a obtenção de dados qualitativos e quantitativos auxiliam a investigação e a fidedignidade quanto a realidade apurada durante o processo de diagnóstico. A partir deste conjunto metodológico os pesquisadores podem analisar a concepção de cada percepção dos grupos estudados, de cada participante, de toda à comunidade educativa. Desta forma, o pesquisador se aproxima da multidimensionalidade dos sujeitos e objetos de pesquisa e contribui para que os problemas sejam abordados de forma sistêmica.

Uma caixa de ferramentas complexa e com dispendioso uso de matérias deve ser pensado com muita parcimônia, uma vez que os participantes podem não compreender a formulação conceitual e a necessidade de utilização. Recomendamos aos pesquisadores que utilizem uma caixa de ferramentas mais simples e a utilização de materiais acessíveis aos participantes, desde que cumpram os objetivos propostos. A confecção de diagramas, por exemplo, utilizando cartolinas e giz de cera com crianças, é tanto um momento de expressão da realidade que desejamos investigar, quanto uma possibilidade lúdica de interação entre os indivíduos; os métodos devem aglutinar e não dividir ou confundir os participantes. Sempre é urgente pensar em metodologias que envolvam gastos reduzidos, permitindo a universalidade do seu uso.

Após a fase de contato, faz-se necessário reavaliar os objetivos da pesquisa, compreender se as indagações iniciais dos pesquisadores realmente são validas perante a realidade estudada. $\mathrm{Na}$ fase de planejar estas questões devem ser postas e discutidas, bem como a escolha da caixa de ferramentas. Questões como: Quem estará na equipe DRP? Quando vai ser realizado o processo de diagnóstico? Onde será efetuada a pesquisa? Que 
materiais serão usados para documentar os resultados de acordo com os métodos e ferramentas eleitos? (VERDEJO, 2010, p. 23-24) auxiliam o grupo nesta fase.

Tanto a fase de contato como a fase de planejar percorrem toda a pesquisa, o DRP é uma metodologia que tenta captar as especificidades de cada recorte de campo sendo importante ressaltar que o contato (o "saber onde pisa") e o planejamento ("como vamos pisar") são contínuos, o que torna a ferramenta atrativa por sua capacidade de adaptação ao campo.

Partimos então para a pesquisa de campo (fase campo do diagrama), onde ocorre de fato o contato com a comunidade. Inicialmente, devem ser esclarecidos os procedimentos, objetivos e limites da prática planejada, esses esclarecimentos são importantes para que não se criem expectativas que mais tarde não possam ser atendidas.

$\mathrm{Na}$ fase de campo ocorrem o maior número de problemas, por ser justamente a etapa que não necessariamente seguirá à risca o que é planejado, assim a equipe de pesquisadores necessita apresentar-se disposta a alterar e remodelar as ações e atividades anteriormente planejadas.

Nesta fase é posto em prática todo o aparato metodológico planejado. Além da identificação dos problemas e limitações, os pesquisadores devem buscar compreender suas causas, efeitos e as alternativas viáveis para a resolução a partir da integração dos participantes com a equipe mediadora do processo. Após esta fase, procedemos com a análise dos dados obtidos (fase de análise), sendo ideal que, ao menos, uma parte dos participantes esteja presente e tome parte no processo.

No final do percurso metodológico, os dados devem ser revisitados e revisados junto à comunidade educativa, através de uma apresentação ampla, formulando a fase final da pesquisa. Essa apresentação deve sempre contemplar a linguagem dos participantes, sendo a construção de diferentes tipos de apresentações e relatórios, visando cada público específico, ideal para socializar todos os resultados obtidos, o que já torna possível a implementação das alternativas encontradas para a resolução dos problemas (VERDEJO, 2010).

A partir das reflexões mediadas pelo DRP os indivíduos são levados a pensar sua própria realidade, o que pode favorecer o empoderamento, a emancipação dos participantes e a tomada de consciência, por meio das interações sociais propiciadas, frente a sua própria realidade (PEREIRA, 2001). Este fornece as comunidades educativas estudadas a possibilidade de obter resultados concretos, de forma rápida, através do processo e dos relatórios e apresentações. Este é o resultado básico esperado em qualquer utilização da metodologia. 
Os dados e análises podem ser utilizados para a formulação de políticas públicas com maior possibilidade de sucesso tendo em vista que, quando pensadas a partir dos sujeitos participantes têm maior possibilidade de mitigar falhas, principalmente em seu processo de implementação (DENHARDT, 2012); facilitando a criação, implementação e/ou adaptação de projetos à realidade escolar como soluções para os possíveis problemas estudados (AMADO; CRISTALINO; HERNÁNDEZ, 2004); capacitam programas e projetos de ensino, pesquisa, cultura e extensão universitária à mediação de saberes mais próxima à realidade; assim, respondendo a variadas demandas sociais e de pesquisa.

O DRP não pretende formular diagnósticos permanentes, pois o ambiente é dinâmico e está em constante mudança, este, também, não é um processo que finaliza na entrega do relatório/apresentação, ele é um processo reflexivo de análise, (re)planejamento e tomada de decisão (FREITAS; FREITAS; DIAS, 2012, p. 74; VERDEJO, 2010, p. 63).

Salientamos que as escolhas metodológicas devem estar em vistas a participação dos sujeitos e a multiplicidade das naturezas de pesquisa deve ser considerada. Buscar estas formas e análises é importante para a pesquisa, pois, quando aliadas, se mostram eficientes na tentativa de ampliar o processo democrático no uso de metodologias de cunho participativo (HERNÁNDES, 2013, p. 54).

\section{Considerações finais}

A pesquisa em educação tem percorrido um longo caminho na direção de métodos e técnicas que possibilitem aos pesquisadores uma multidimensionalidade de abordagens de pesquisa, com isto, a aproximação entre pesquisador e objeto/sujeito de pesquisa, com a utilização de métodos mistos, formulam o paradigma contemporâneo do campo da pesquisa.

Faz-se necessário superar a dicotomia quanto à natureza da pesquisa, se qualitativa ou quantitativa, entendendo suas possibilidades e limitações, considerando o contexto micro e/ou macro no qual a investigação se insere, refletindo sobre este leque de possibilidades nascidos das interações metodológicas.

O DRP nasce em um contexto similar ao do campo da pesquisa em educação nos anos 80, onde, em ambos os casos, a transferência tecnológica e os dados gerais obtidos a partir de pesquisas generalistas, não dão mais conta de responder a demandas especificas de seu tempo.

Nesse interim, ele se apresenta como alternativa metodológica para a área da educação, possibilitando o avanço da fronteira do conhecimento, através de ferramentas fundamentadas na participação e com abordagem de natureza mista, viabilizando a construção 
de diagnóstico condizentes com as reais necessidades das comunidades educativas investigadas. Suas principais vantagens são a flexibilidade, a triangulação de dados, a participação dos sujeitos envolvidos na pesquisa, a multiplicidade de métodos de coleta e análise de dados e a mediação em vistas a reconhecer problemas e suas soluções em conjunto aos participantes.

Todo DRP tem por objetivo apresentar uma contribuição significativa aos sujeitos participantes da pesquisa por meio de relatórios e apresentações, a partir dos dados obtidos e analisados, que os auxiliem a refletir sobre sua própria realidade em todo o processo, fomentando um espaço de descoberta colaborativa de soluções que podem facilitar a criação de projetos educativos, mudanças de rumo e a formulação e proposição de políticas públicas mais condizentes com a realidade. Para além da pesquisa e do diagnóstico, o DRP contribui socialmente para a tomada de decisão sobre o futuro da comunidade educativa investigada.

Para estudos futuros, a apresentação de diagnósticos e proposição de resolução das situações problema por parte das comunidades educativas estudadas, a exposição de novas ferramentas e métodos para compor sua caixa de ferramentas, pesquisas comparativas entre o DRP e métodos como a Pesquisa-ação e o Estudo de Caso, também se mostram como alternativas interessantes que podem contribuir tanto para a evolução e refinamento do DRP quanto ao campo da pesquisa em educação.

\section{Referências}

AMADO, Rosa; CRISTALINO, Flor; HERNÁNDEZ, Egyanis. El diagnóstico participativo como herramienta para la elaboración de proyectos educativos. Ágora, Trujillo, v. 13, n. 1, jan./jun. 2004. Disponível em:

<http://www.saber.ula.ve/bitstream/123456789/17575/2/articulo_4.pdf >. Acesso em: 12 abr. 2017.

ANDRÉ, Marli. Questões sobre os fins e sobre os métodos de pesquisa em educação. Revista Eletrônica de Educação, São Paulo, v. 1, n. 1, set. 2007. Disponível em:

<http://www.reveduc.ufscar.br/index.php/reveduc/article/view/6>. Acesso em: 12 abr. 2017.

ANTUNES, Jeferson; LIMA, Jânio do Nascimento; TEIXEIRA, Wesley Castro; SOUSA; Lizandra de Barros de; CAVALCANTE; Samuel Onofre. Considerações e resultados acerca da aplicação da criativa: metodologia educativa fomentada por meio dos jogos cooperativos. Cadernos de Pesquisa: Pensamento Educacional, Curitiba, v. 11, n. 27, jan./abr. 2016.

Disponível em:

<http://universidadetuiuti.utp.br/Cadernos_de_Pesquisa/cad_pesq_27/pdf_27/art_1.pdf>. Acesso em: 12 abr. 2017. 
BONFIM, Z. Á. C. Cidade e afetividade: estima e construção dos mapas afetivos de Barcelona e São Paulo. 238 f. Tese (Doutorado) - Pontifícia Universidade Católica de São Paulo, São Paulo, 2003.

BRAUN, Virginia; CLARKE, Victoria. Using thematic analysis in psychology. Qualitative Research in Psychology, Philadelphia, v. 3, n. 2, jul. 2008. Disponível em: <http://www.tandfonline.com/doi/abs/10.1191/1478088706qp063oa>. Acesso em: 12 abr. 2017.

CHAMBERS, Robert. Rural appraisal: rapid, relaxed and participatory. London: Institute of Development Studies, 1992.

CHAMBERS, Robert. Rapid rural appraisal: rationale and repertoire. Public administration and development, Nottingham, v. 1, n. 2, abr./jun. 1981. Disponível em:

<http://onlinelibrary.wiley.com/doi/10.1002/pad.4230010202/full>. Acesso em: 12 abr. 2017.

CAMPOS, Maria Malta. Pesquisa em educação: algumas questões para debate. Educação \& Linguagem, São Paulo, v. 9, n. 14, jul./dez. 2006.

CAMPOS, Maria Malta; FÁVERO, Osmar. A pesquisa em educação no Brasil. Cadernos de Pesquisa, São Paulo, n. 88, v. 1, jan./abr. 1994. Disponível em:

<http://publicacoes.fcc.org.br/ojs/index.php/cp/article/view/911>. Acesso em: 12 abr. 2017.

CARRUTHERS, Ian; CHAMBERS, Robert. Rapid appraisal for rural development.

Agriculture Administration, England, n. 8, v. 6, nov. 1981. Disponível em: <http://www.sciencedirect.com/science/article/pii/0309586X81900364>. Acesso em: 12 abr. 2017.

DAL-FARRA, Rossano André; LOPES, Paulo Tadeu Campos. Métodos mistos de pesquisa em educação: pressupostos teóricos. Nuances: estudos sobre Educação, Presidente Prudente, v. 24, n. 3, set./dez. 2013. Disponível em:

$<$ http://revista.fct.unesp.br/index.php/Nuances/article/view/2698/2362>. Acesso em: 12 abr. 2017.

DENHARDT, Robert B. Teorias da administração pública. São Paulo: Cengage Learning, 2012.

DUNNE, David; MARTIN, Roger. Design Thinking and How It Will Change Management Education: an Interview and Discussion. Academy of Management Learning \& Education, v. 5, n. 4, dez. 2006. Disponível em: 〈http://amle.aom.org/content/5/4/512.full.pdf+html〉. Acesso em: 12 abr. 2017.

FEYERABEND, Paul. Contra o método. Rio de Janeiro: Francisco Alves, 1977.

FLICK, Uwe. Introdução a pesquisa qualitativa. 3. ed. Porto Alegre: Artmed, 2009.

FLORIANI, Dimas. Marcos Conceituais do Desenvolvimento da Interdisciplinaridade. In: PHILIPPI JR., Arlindo; TUCCI, Carlos E. Morelli; HOGAN, Daniel Joseph;

NAVEGANTES, Raul. Interdisciplinaridade em ciências ambientais. São Paulo: Signus, 2000 .

FREIRE, Paulo. A importância do ato de ler: em três artigos que se completam. São Paulo: Cortez \& Autores Associados, 1991. 
FREIRE, Paulo. Pedagogia da autonomia: saberes necessários à prática educativa. 24. ed. São Paulo: Paz e Terra, 1996.

FREITAS, Alan Ferreira de; FREITAS, Alair Ferreira de; DIAS, Marcelo Miná. O uso do Diagnóstico Rápido Participativo (DRP) como metodologia de projetos de extensão universitária. Em Extensão, Uberlândia, v. 11, n. 2, 2012. Disponível em: <http://www.seer.ufu.br/index.php/revextensao/article/view/20780>. Acesso em: 12 abr. 2017.

GATTI, Bernardete Angelina. A construção metodológica da pesquisa em educação: desafios. RBPAE, Goiânia, v. 28, n. 1, jan./abr. 2012. Disponível em:

<http://seer.ufrgs.br/rbpae/article/view/36066>. Acesso em: 12 abr. 2017.

GATTI, Bernardete Angelina. Implicações e perspectivas da pesquisa educacional no Brasil contemporâneo. Cadernos de pesquisa, São Paulo, n. 113, v. 2, jul. 2001. Disponível em: <http://publicacoes.fcc.org.br/ojs/index.php/cp/article/view/600>. Acesso em: 12 abr. 2017.

GIL, Antônio Carlos. Métodos e técnicas de pesquisa social. 6. ed. São Paulo: Atlas, 2012.

HERNÁNDES, Rocío Valderrama. Diagnóstico Participativo con Cartografía Social. Innovaciones en metodologia Investigación-Acción Participativa (IAP). Anduli, Sevilla, n. 12, v. 1, 2013. Disponível em: <http://institucional.us.es/revistas/anduli/12/art_3.pdf>. Acesso em: 12 abr. 2017.

LEFEVRE, Ana Maria; LEFEVRE, Fernando. Pesquisa de representação social: um enfoque qualiquantitativo. 2. ed. Brasília: Liber Livro, 2012.

LOURO, Guacira Lopes. Gênero, sexualidade e educação: uma perspectiva pósestruturalista. Petrópolis: Vozes, 1997.

MEIRINHOS, Manuel; OSÓRIO, António. O estudo de caso como estratégia de investigação em educação. EDUSER: revista de educação, Bragança, v. 2, n. 2, 2010. Disponível em: $<$ https://bibliotecadigital.ipb.pt/bitstream/10198/3961/1/O\%20estudo\%20de\%20caso\%20com o\%20estrat\%C3\%A9gia\%20de\%20investiga\%C3\%A7\%C3\%A3o\%20em\%20educa\%C3\%A 7\%C3\%A3o.pdf>. Acesso em: 12 abr. 2017.

MINAYO, Maria Cecília de Souza. Pesquisa social: teoria, método e criatividade. 33. ed. Petrópolis: Vozes, 2013.

PENN, Gemma. Analise semiótica de imagens paradas. In: BAUER, Martin W.; GASKELL, George. Pesquisa qualitativa com texto, imagem e som: um manual prático. 6 . ed. Rio de Janeiro: Vozes, 2007.

PEREIRA, Guilherme; ORTIGÃO, Maria Isabel Ramalho. Pesquisa quantitativa em educação: algumas considerações. Revista Periferia, Duque de Caxias, v. 8, n. 1, jan./jun. 2016. Disponível em: <http://www.epublicacoes.uerj.br/index.php/periferia/article/view/27341>. Acesso em: 12 abr. 2017.

PEREIRA, José Roberto. Visões mediadoras e o papel dos diagnósticos participativos na organização de assentamentos rurais. Organizações Rurais \& Agroindustriais, Lavras, v. 3, n. 2, 2001. Disponível em: <http://revista.dae.ufla.br/index.php/ora/article/view/268>. Acesso em: 12 abr. 2017. 
PEREIRA, José Roberto. Diagnóstico Rápido Participativo Emancipador (DRPE) Metodologia. Brasília: INCRA/BID, 1998.

RIFTKIN, Susan B. Paradigms lost: toward a new understanding of community participation in health programmes. Acta Tropica, Miami, n. 61, v. 2, 1996. Disponível em: <http://www.sciencedirect.com/science/article/pii/0001706X9500105N>. Acesso em: $12 \mathrm{abr}$. 2017.

ROTHER, Edna Terezinha. Revisão sistemática x revisão narrativa. Acta Paulista de Enfermagem, São Paulo, n. 20, v. 2, abr./jun. 2007. Disponível em: <http://www.scielo.br/scielo.php?script=sci_arttext\&pid=S0103-21002007000200001>. Acesso em: 12 abr. 2017.

SANTOS, André Michel dos; GRAEFF, Betina; KERN, Francisco Arseli; DENTZ, Marta von. Análise de Pesquisas em Educação: um enfoque nas políticas educacionais contemporâneas. Trajetória Multicursos, Osório, v. 7, n. 1, jun./ago. 2016. Disponível em: <http://sys.facos.edu.br/ojs/index.php/trajetoria/article/view/93>. Acesso em: 12 abr. 2017.

SANTOS, Leonardo Bis dos. O conflito social como ferramenta teórica para interpretação histórica e sociológica. Boletim do Museu Paraense Emílio Goeldi. Ciências Humanas, Pará, v. 9, n. 2, maio-ago. 2014. Disponível em:

<http://www.scielo.br/pdf/bgoeldi/v9n2/a15v9n2.pdf>. Acesso em: 12 abr. 2017.

SOUZA, Murilo Mendonça Oliveira. A utilização de metodologias de diagnóstico e planejamento participativo em assentamentos rurais: o diagnóstico rural/rápido participativo (DRP). Em Extensão, Uberlândia, v. 8, n. 1, 2009. Disponível em:

<http://www.seer.ufu.br/index.php/revextensao/article/view/20380>. Acesso em: 12 abr. 2017.

THIOLLENT, Michel. Metodologia da Pesquisa-ação. 7. ed. São Paulo: Cortez; 1996.

VERDEJO, Miguel Expósito. Diagnóstico rural participativo: guia prático DRP. Brasília: MDA/Secretaria da Agricultura Familiar, 2010.

${ }^{1}$ Jeferson Antunes Universidade Federal do Ceará | Faculdade de Educação | Programa de Pós-graduação em Educação Fortaleza | CE | Brasil. Contato: jeferson.antunes@aluno.ufca.edu.br ORCID http://orcid.org/0000-0002-2969-5788

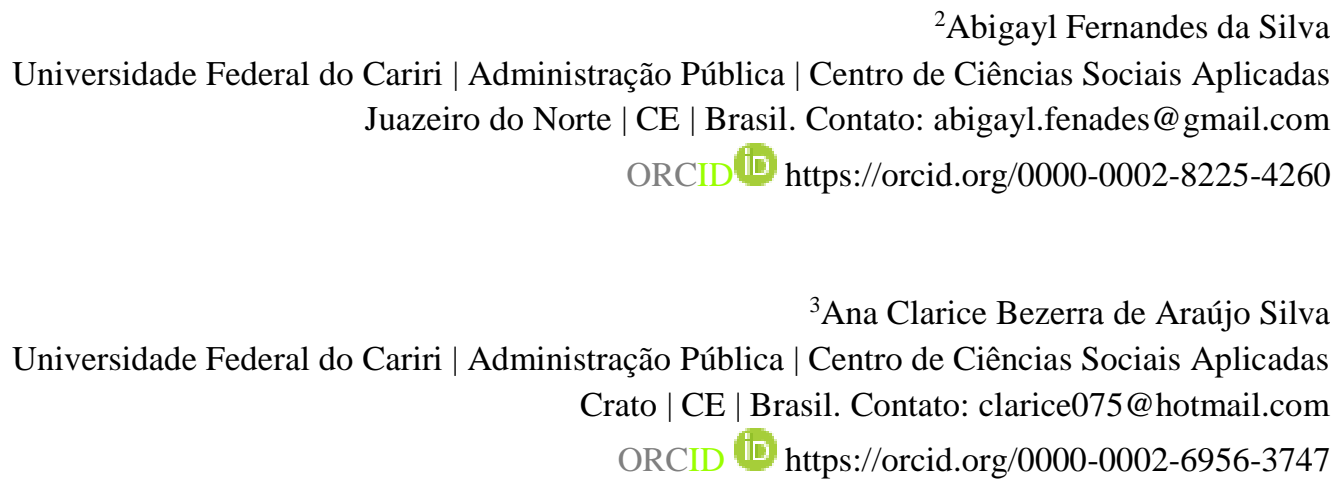


Jeferson Antunes, Abigayl Fernandes da Silva,

Ana Clarice Bezerra de Araújo Silva, Zuleide Fernandes de Queiroz

${ }^{4}$ Zuleide Fernandes de Queiroz

Universidade Regional do Cariri | Pedagogia | Departamento de Educação

Crato |CE | Brasil. Contato: zuleidefqueiroz@gmail.com

ORCID (iD) https://orcid.org/0000-0003-3174-4750

Artigo recebido em 29 de maio de 2017 e aprovado em 25 de julho de 2018. 